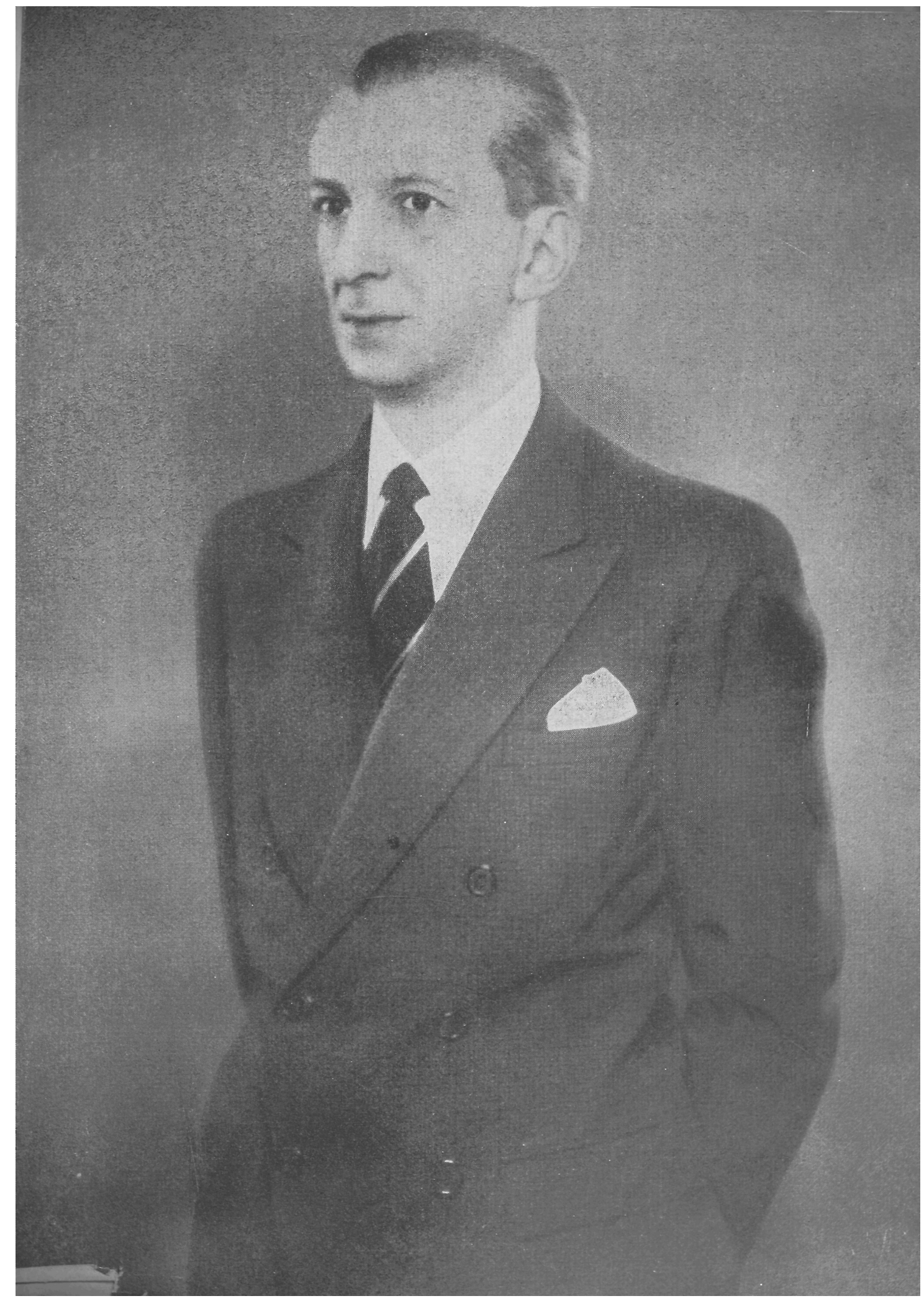




\section{PROFESSOR DR. VICENTE RÁO}

Nasceu o professor Vicente Rảo a 16 de Junho de 1892 , filho de Nunciato Ráo e de D. Raquel Sicilia Ráo.

Bacharelou-se, em Dezembro de 1907, pelo Ginásio Nossa Senhora do Carmo em São Paulo, em Ciências e Letras.

Matriculado na Faculdade de Direito de São Paulo, recebeu o gráu de bacharel em Ciências Jurídicas e Sociais em 1912, após curso brilhante. Já no ano anterior se graduara pela Faculdade de Filosofia e Letras de São Paulo, agregada a Universidade de Louvain (Bélgica).

Assim preparado enveredou sua atividade para a advocacia e para o jornalismo. Neste ramo foi um dos redatores do Jornal do Comércio de São Paulo e diretor do São Paulo Jornal. Teve aí oportunidade de demonstrar suas aptidões combativas, defendendo sempre as causas mais nobres, sendo um dos esteios dos direitos populares.

$\mathrm{Na}$ advocacia, seus pareceres têm sido sempre havidos como bem fundamentados e baseados no que há de mais coerente na ordem jurídica. É advogado de renome nacional, sempre apreciado pela sua cultura, pelo seu grande saber, pela criteriosa maneira de conduzir as causas que lhe são confiadas.

Embora sempre atarefado em sua banca de advogado, teve tempo para preparar suas teses, que defendeu perante a Faculdade na Cadeira de Direito Civil. Aprovado em concurso, como era de esperar, foi nomeado Professor Catedrático por decreto de 4 de Julho de 1927, tendo to- 
mado posse no dia 15 do mesmo mês, quando recebeu o gráu de Doutor em Direito.

Além de suas atividades na cadeira de Direito Civil no curso de bacharelado, em 1934 foi também professor catedrático de Direito Público no curso de Doutorado.

Foi também Presidente do Instituto da Ordem dos Advogados de São Paulo.

Aposentado compulsòriamente em 13 de Janeiro de 1939 juntamente com outros professores desta Casa, na vigência do govêrno ditatorial, foi reintegrado em sua cadeira pelo decreto 3298 de 22 de Maio de 1941.

Não satisfeito com a sua atividade de professor e de advogado, sobrou-lhe ainda tempo para intervir nas questões políticas nacionais e estaduais. É assim que, em 1930 fez parte do govêrno provisório de São Paulo, e, logo de-pois, Ministro dos negócios do Interior e da Justiça. Em ambos êstes cargos teve o Professor Ráo ocasião de trabalhar dedicadamente em benefỉcio do Brasil e de São Paulo.

Delegado do Brasil, em 1950, à V Assembléia Geral da Organização das Nações Unidas, deu, com sua inteligência esclarecida, grande brilho a nossa representação naquela Assembléia, tornando o nome de nossa Pátria respeitado.

Publicou, o Professor Vicente Ráo, vários livros, todos referentes a sua especialidade, além de grande cópia de arrazoados e pareceres, colaborando ainda em inúmeras revistas. Dentre suas obras, destacam-se as seguintes:

\section{PAREGERES :}

Dívida de casal - Cobrança contra um dos cônjuges, vários annos depois do desquite e fallecimento dos primitivos titulares do crédito _ Omissão dêste nos inventários havidos _ Pressumpçẩo de pagamento - in Revista dos Tribunais - São Paulo — 1934 vrolume 92 - página 272.

Cousa julgada - Pleiteia com nova "causa de pedir" e nâo usa de méro "argumento" quem pede, em ação ordinária, restituição de 
imposto, por isenção, quando no exercicio fiscal, sòmente foi discutido e decidido o direito da Fazenda a receber imposto majorado no curso do exercício - in Justiça - Pôrto Alegre - 1940-1941 volume 18 - página 43.

Conflito de acções divisórias - in Revista dos Tribunais São Paulo - 1927 - suplemento, nưmero 1 - páginas 399 a 416 Juntamente com José Ulpiano Pinto de Sousa.

Compra e venda mercantil - Entregas parciaes, cada mês, da mercadoria - Estipulação do pagamento adiantado de certa importancia por conta de cada entrega - Não entrega da mercadoria e falta do pagamento adiantado - Discussão sôbre a interpretaçâo do contracto e sobre a mora em direito commercial - Applicaçâo dos arts. 138 e 205 do Código de Commercio - in Revista dos Tribunaes - São Paulo — 1939 - volume 120 — páginas 431 a 437 $\rightarrow$ Juntamente icom Jorge Americano.

Abuso do direito - Seu conceito na legislacấo civil brasileira - - in Revista dos Tribunaes - São Paulo - 1930 — volume 7x - páginas 447.

Annulaçãa de casamento - Erro essencial sobre a pessoa Prazo de prescrição de acção - contagem quanto aos actos anteriores à lei n. 13 de 29 de janeiro de 1935 - in Revista dos Tribunaes — São Paulo - 1942 — volume 136 — páginas 13.

\section{ARTIGOS E DISCURSOS:}

Um esboço de constituição federal - in Revista da Faculdade de Direito — São Paulo — 1934 - volume 30 - página 12

o estado de guerra - A suspensão das garantias não alterou a estructura do regimen - in Revista Jundiciaria - São Paulo - 1936 - volume 2.

Azevedo Marques - in Revista da Faculdade de Direito - São Paulo - 1943-1944 — volume 39 — página 9.

Congresso nacional de direito judiciário - Discurso - in Justiça Pôrto Alegre - 1936 - volume 9 — página 211.

Direito commercial brasileiro - in Revista de Direito commercial - Rio de Janeiro - 1931 - volume 1 - página 47.

o direito de familia da legislação soviética - in Archivo Judiciário-Rio de Janeiro - 1929 - volume 12 - página 67 do suplemento - Conferência - (publicada também nas outras seguintes revistas: Revistas ide direito - Rio de Janeiro - 1930 — volume 96 - página 487; Pandectas brasileiras — Rio de Janeiro - 
1929 - volume sátimo - primeira parte - página 182; Boletim do Instituto da Ordem dos Advogados Brasileiros - Rio de Janeiro - 1929 - volume VI — página 93; Revista da Faculdade de Direito — São Paulo — 1929 - volume 25 — página 255).

Proteç̧ão legal ao titulo dos jornaes e revistas - in Revista dos Tribunaes - São Paulo - 1919 - volume 31 - página 107.

Projecto do Codigo do Processo Penal da República dos Estados Unidos do Brasil - in Revista da Faculdade de Direito - São Paulo - 1938 - volume 34 - fascículo III - página 137.

Professor Francisco Antonio de Almeida Morato - Discurso — in Revista da Faculdade de Direito - São Paulo - maio-agôsto 1938 — volume XXXIV - fascículo II — página 62.

Os problemas sociaes e politicos - In Syn-Diké - São Paulo - 1936 - número 15 - página 27.

o jubileu literario do conselheiro Ruy Barbosa - Discurso e mensagem - in Revista dos Tribunais — São Paulo - 1918 volume 28 - página 28.

Nacionalização do direito - A questão do methodo no ensino do direito civil - in Revista da Faculdade de Direito - São Paulo - 1928 - volume 24 - página 185.

Novas formas de reorganização politica -- in Revista da Faculdxde de Direito — São Paulo — 1933 — volume 29 — página 77.

\section{LIVROS :}

Da capacidade civil da mulher casada - Saraiva \& Cia. editores — São Paulo - 1922 - Estudo theorico e pratico segundo o codigo civil brasileiro.

Direitos da mulher casada sobre o produto do seu trabalho Dissertação para o concurso à cadeira de direito civil da Faculdade de Direito - São Paulo — sem editor — sem data.

Posse de direitos pessoaes - F. Fragale \& Cia. - São Paulo - sem data.

Direito de familia dos Soviets - Cia. Editora Nacional - São Paulo - 1932 - Contendo o Código das Leis do Casamento, da familia e da tutela - traduzido e comentado - $2^{\text {a }}$ edição.

o Direito e a vida dos Direitos - Max Limonad - São Paulo - 1952 - volume I - tomos I e II.

Possuidor da alta noção de civilismo e democracia, tem sido um combatente de boas causas, e orientador seguro de seus alunos, com suas magníficas preleçôes, sem- 
pre empolgantes. Suia última obra publicada, $O$ Direito $e$ a Vida dos Direitos, da qual apenas o primeiro volume apareceu, dá bem uma idéia do prófundo pensador e grande mestre de direito que é Vicente Ráo. Desde as primeiras palavras do livro, quando trata da origem, essência e finalidade social do direito, quando faz o estudo dos sistemas de direito positivo em vários países, até o estudo das obrigações, tudo mostra as qualidades do grande professor. 